\title{
Results From Spain's 2016 Report Card on Physical Activity for Children and Youth
}

\author{
Blanca Roman-Viñas, Jorge Marin, Mairena Sánchez-López, Susana Aznar, Rosaura Leis, \\ Raquel Aparicio-Ugarriza, Helmut Schroder, Rocío Ortiz-Moncada, German Vicente, \\ Marcela González-Gross, and Lluís Serra-Majem
}

\begin{abstract}
Background: The first Active Healthy Kids Spanish Report Card aims to gather the most robust information about physical activity (PA) and sedentary behavior of children and adolescents. Methods: A Research Working Group of experts on PA and sport sciences was convened. A comprehensive data search, based on a review of the literature, dissertations, gray literature, and experts' nonpublished data, was conducted to identify the best sources to grade each indicator following the procedures and methodology outlined by the Active Healthy Kids Canada Report Card model. Results: Overall PA (based on objective and self-reported methods) was graded as $D$-, Organized Sports Participation as $B$, Active Play as $C+$, Active Transportation as $C$, Sedentary Behavior as $D$, School as $C$, and Family and Peers as Incomplete, Community and the Built Environment as Incomplete, and Government as Incomplete. Conclusions: Spanish children and adolescents showed low levels of adherence to PA and sedentary behavior guidelines, especially females and adolescents. There is a need to achieve consensus and harmonize methods to evaluate PA and sedentary behavior to monitor changes over time and to evaluate the effectiveness of policies to promote PA.
\end{abstract}

Keywords: sedentary lifestyle, exercise, child health, adolescents, active transportation

In children and adolescents, adiposity, cardiovascular biomarkers, bone health, physical fitness, quality of life, motor skills development, and psychological distress have been associated with physical activity (PA), measured either in terms of minutes dedicated to total, light, moderate, and vigorous intensities ${ }^{1-4}$ or sedentary time. 1,5,6 Current Spanish PA guidelines recommend that children and youth should accumulate at least 60 minutes of moderate-tovigorous PA (MVPA) daily and reduce screen time to no more than 2 hours daily. ${ }^{7}$ Nevertheless, Spanish children have PA habits that are far from fulfilling the recommendations. According to the ANIBES study conducted in $2013,48.4 \%$ of children aged 9 to 12 years old and $62.6 \%$ of adolescents aged 13 to 17 years are not meeting the recommendations of at least 60 minutes of MVPA daily. ${ }^{8}$

Spain is a country of more than 45 million inhabitants made up of 17 autonomous regions with self-government in several areas, such as schools, universities, health, social services, etc. The overall framework and guidelines of the education and health systems are defined at the national level and the ministries or departments of education and health from the 17 autonomous communities develop and manage their own systems based on these guidelines. As such, there are some differences throughout the country in terms of scholar curriculum application, promotion, and monitoring strategies of PA, etc. The Active Healthy Kids Spanish Report Card was developed following the procedures of the Active Healthy Kids Canada Report Card and represents an opportunity to gather the information for every key PA indicator, to identify gaps, and to make Spanish policy makers aware of the situation and the need to increase funds for promoting PA initiatives.

The purpose of this article is to describe the procedures and summarize the results of the findings from a review of the PA levels of Spanish children and adolescents conducted to develop the Active Healthy Kids Spanish Report Card.

Roman-Viñas is with the Dept of Physical Activity and Sport Sciences, FPCEE Blanquerna, Universitat Ramon Llull; the Nutrition Research Foundation, Barcelona, Spain; and CIBER Fisiopatología de la Obesidad y Nutrición (CIBERobn), Instituto de Salud Carlos III (ISCIII). Marin and Vicente are with GENUD (Growth, Exercise, NUtrition and Development), Faculty of Health and Sport Sciences, University of Zaragoza. Sánchez-López is with the Social and Health Care Research Center, Universidad de Castilla-La Mancha, Cuenca, Spain; and the Faculty of Education, Universidad de Castilla-La Mancha, Ciudad Real, Spain. Aznar is with the PAFS Research group, Faculty of Sports Sciences, University of Castilla-La Mancha, Madrid, Spain. Leis is with the CIBER Fisiopatología de la Obesidad y Nutrición (CIBERobn), Instituto de Salud Carlos III (ISCIII); and the Pediatric Nutrition Research Group-IDIS-Hospital Clínico Universitario de Santiago, University of Santiago de Compostela, Spain. Aparicio-Ugarriza is with the ImFINE Research Group, Dept of Health and Human Performance, Faculty of Physical Activity and Sport Sciences, INEF, Technical University of Madrid. Schroder is with the Cardiovascular Risk and Nutrition Research Group (CARIN), IMIM (Hospital del Mar Medical Research Institute); and CIBER Epidemiology and Public Health (CIBERESP), Instituto de Salud Carlos III, Spain. Ortiz-Moncada is with the Food and Nutrition Research Group, Dept of Community Nursing, Preventive Medicine, and Public Health and History of Science, University of Alicante, Spain. González-Gross is with the CIBER Fisiopatología de la Obesidad y Nutrición (CIBERobn), Instituto de Salud Carlos III (ISCIII); and the ImFINE Research Group, Dept of Health and Human Performance, Faculty of Physical Activity and Sport Sciences, INEF, Technical University of Madrid. Serra-Majem is with the Nutrition Research Foundation, Barcelona, Spain; CIBER Fisiopatología de la Obesidad y Nutrición (CIBERobn), Instituto de Salud Carlos III (ISCIII); and the Research Institute of Biomedical and Health Sciences, Department of Clinical Sciences, University of Las Palmas de Gran Canaria. Roman-Viñas (dietmed@ fin.pcb.ub.es) is corresponding author. 


\section{Methods}

Active Healthy Kids Report Cards have shown to be an effective and efficient method of summarizing the available literature, ${ }^{9}$ which will hopefully aid in the adoption and creation of PA strategies and policies that are most appropriate for Spain. The Spanish Healthy Active Kids Report Card was coordinated and developed by the Nutrition Research Foundation. A research working group (RWG) of established experts on PA and health from 6 Spanish Universities (University of Las Palmas de Gran Canaria, University of Zaragoza, University of Castilla-La Mancha, Technical University of Madrid, University of Santiago de Compostela, and University of Alicante) and 2 research groups (Hospital del Mar Medical Research Institute, IMIM and Nutrition Research Foundation) was convened.

The RWG chair (BRV) was responsible for conducting the narrative review, identifying and gathering the key information, and collecting additional publications obtained from the RWG experts. The data were grouped in 9 indicators following the Active Healthy Kids Canada PA Report Card protocol ${ }^{10}$ and extracted in a spreadsheet. The RWG experts were provided with the preliminary data and were instructed to include additional information. The members of the RWG met in February 2016 to agree on the key data to be included in the report and to assess the grade assigned to each indicator. The grade for each indicator was based on the percentage of children and youth meeting a defined benchmark: $A$ is $81 \%$ to $100 \%$; $B$ is $61 \%$ to $80 \%$; $C$ is $41 \%$ to $60 \%, D$ is $21 \%$ to $40 \%$; $F$ is $0 \%$ to $20 \%$; INC is incomplete data. When necessary, a "+" or "-" sign was included, for instance if data trends indicated an improvement (the "+" sign) or if gender differences where too big (the "-" sign).

One week before the meeting the RWG members were provided with all the data collected in a spreadsheet. They were asked to check the data, decide what data was most relevant, and grade the indicators. During the meeting the researchers convened the quality of the data and proposed a grading. The criteria for qualifying the data was based on the representativeness of the sample, the sample size, the year of the study, and the methods used to assess the information on PA.

The indicators included in the Spanish report were: Overall Physical Activity Levels, Organized Sport Participation, Active Play, Active Transportation, Sedentary Behaviors, Family and Peers (infrastructure, support, parental/peer behaviors), School (infrastructure, policies, and programs), Community and the Built Environment (infrastructure, policies, programs, safety), and Government (strategies, policies, investments).

The data sources included for the analysis are shown in Table 1.

\section{Results and Discussion}

The 2016 Spanish Report Card is the first assessment of PA according to the 9 indicators suggested by Active Healthy Kids Canada. The grades assigned to each indicator are included in Table 2. Figure 1 shows the front cover of the 2016 Spanish Report Card.

\section{Overall Physical Activity: D-}

The score of $D$ - was obtained based on the percentage of children and youth achieving the recommendation of 60 minutes of MVPA daily. The negative sign ("-") was assigned to emphasize the differences between genders, with females being less active than males in all the age groups. Data obtained from the IDEFICS study using objective methods indicated that only $30 \%$ males and $12 \%$ of females ( 2 to 10 years old), respectively, achieved the recommendations. ${ }^{22}$ For children aged 9 years old and adolescents aged 15 years old, the achievement of the PA guidelines was the following: $60 \%$

Table 1 Main Data Sources

\begin{tabular}{|c|c|c|c|c|}
\hline Study name & Study year & Study type & Age (years) & $\begin{array}{l}\text { Method to assess } \\
\text { physical activity }\end{array}$ \\
\hline $\begin{array}{l}\text { ALADINO (ALimentación, Actividad Física, Desar- } \\
\text { rollo INfantil y Obesidad-Food, Physical Activity, } \\
\text { Child development and Obesity) }\end{array}$ & $2011-2013$ & Cross-sectional & $6-9$ & Self-reported questionnaire \\
\hline $\begin{array}{l}\text { IDEFICS (Identification and prevention of Dietary- } \\
\text { and lifestyle-induced health EFfects In Children and } \\
\text { infantS) })^{13}\end{array}$ & $2007-2008$ & $\begin{array}{l}\text { Community interven- } \\
\text { tion study }\end{array}$ & $2-10$ & $\begin{array}{l}\text { Accelerometer/self-reported } \\
\text { questionnaire }\end{array}$ \\
\hline $\begin{array}{l}\text { HELENA (Healthy Lifestyle in Europe by Nutrition } \\
\text { in Adolescence) }{ }^{14}\end{array}$ & 2006-2008 & Cross-sectional & 15 & Accelerometer \\
\hline $\begin{array}{l}\text { Spanish National Health Survey (Encuesta Nacional } \\
\text { de Salud) })^{15}\end{array}$ & 2011 & Cross-sectional & $1-14$ & Self-reported questionnaire \\
\hline European Youth Heart Study (EYHS) ${ }^{16}$ & $2008-2010$ & Cross-sectional & 9 and 15 & Accelerometer \\
\hline Health Behavior in School-aged Children (HBSC) ${ }^{17}$ & 2010 & Cross-sectional & $11,13,15$ & Self-reported questionnaire \\
\hline $\begin{array}{l}\text { ANIBES (Anthropometry, Intake and Energy Bal- } \\
\text { ance in Spain) })^{18}\end{array}$ & 2013 & Cross-sectional & $9-17$ & Accelerometer \\
\hline THAO-Child Health Program ${ }^{19}$ & 2012 & $\begin{array}{l}\text { Community-based inter- } \\
\text { vention }\end{array}$ & $6-18$ & Self-reported questionnaire \\
\hline Sporting habits in Spain ${ }^{20}$ & 2015 & Cross-sectional & $6-18$ & Self-reported questionnaire \\
\hline FRESC $^{21}$ & 2012 & Cross-sectional & 14,16 , and 18 & Self-reported questionnaire \\
\hline
\end{tabular}


and $34.1 \%$ for boys and girls, respectively, and $28.8 \%$ and $8.9 \%$ for male and female adolescents, respectively. ${ }^{23}$ For the adolescents group (HELENA study), $58 \%$ of males and $24 \%$ of females aged 15 years met the guidelines. ${ }^{24}$ Based on self-reported data obtained

\section{Table 2 Grades According to Physical Activity Indicator in the 2016 Spanish Report Card on Physical Activity for Children and Youth}

\begin{tabular}{lc}
\hline Indicator & Grades \\
\hline Overall Physical Activity Levels & $D-$ \\
Organized Sport Participation & $B$ \\
Active Play & $C+$ \\
Active Transportation & $C$ \\
Sedentary Behaviors & $D$ \\
Family and Peers & $I N C$ \\
School & $C$ \\
Community and the Built Environment & $I N C$ \\
Government Strategies and Investments & $I N C$ \\
\hline
\end{tabular}

Note. The grade for each indicator is based on the percentage of children and youth meeting a defined benchmark: $A$ is $81 \%$ to $100 \%$; $B$ is $61 \%$ to $80 \%$; $C$ is $41 \%$ to $60 \%, D$ is $21 \%$ to $40 \% ; F$ is $0 \%$ to $20 \%$; INC is Incomplete data.

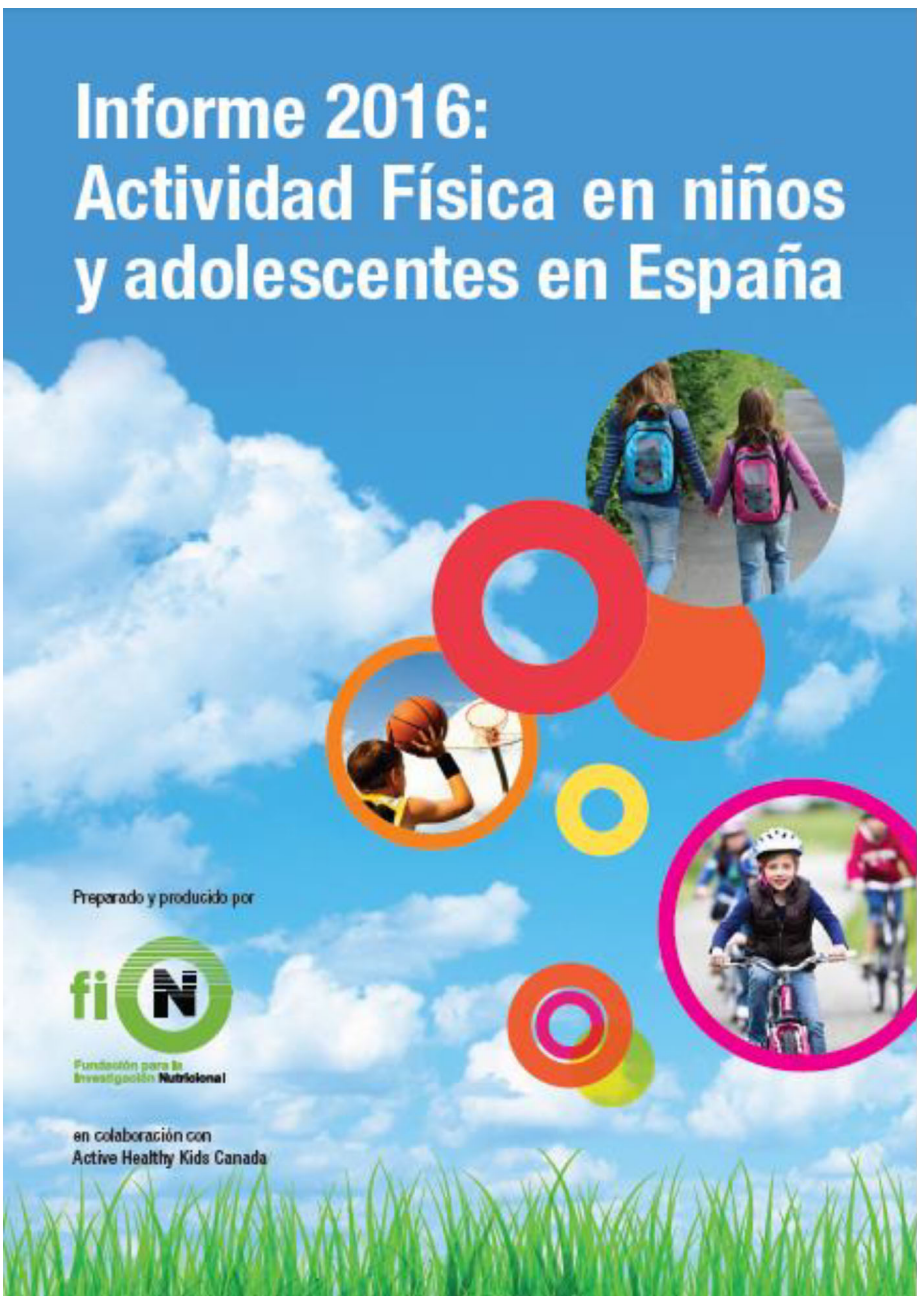

Figure 1 - Front cover of the 2016 Spanish Physical Activity Report Card on Physical Activity for Children and Youth. from a large sample of Spanish participants of the HBSC for 2010, $32 \%$ of 11 - to 12 -year-old children and $15 \%$ of older adolescents (17 to 18 years old) were adequately active. ${ }^{25}$ Data from the ANIBES study collected in 2013 also showed big differences between ages and genders $; 8$ the guidelines were met by $52 \%$ of 9 - to 12 -year-old adolescents and by $37 \%$ of 13 - to 17-year-old adolescents. Regarding gender differences, $56 \%$ of males and $27 \%$ of females were sufficiently active.

\section{Organized Sports Participation: B}

The data were obtained from 3 large sample size studies conducted in children and adolescents ${ }^{11,12,20}$ and a large study conducted in young children (IDEFICS). ${ }^{26}$ The score was assigned according to the percentage of children and youth participating in some type of sport out-of-school at least once a week. Seven percent of males and $6 \%$ of females aged 2 to 5 years met the recommendation; the percentage increased to $46 \%$ and $28 \%$ for males and females aged 6 to 9 years, respectively. ${ }^{26}$ For older children, data from the 2013 ALADINO study indicated that $71 \%$ of males and $61 \%$ of females aged 7 and 8 years did some type of sport at least once a week. ${ }^{11}$ Adolescents' data referred to the percentage of individuals doing some type of organized PA, with $64 \%$ of young adolescents meeting the guidelines (74\% male and $54 \%$ female) and only $50 \%$ of 16 - to 18 -year-old adolescents achieving the recommendations (64\% male and $35 \%$ female). ${ }^{20}$

\section{Active Play: $\mathbf{C +}$}

The indicator was graded $C+$ according to the percentage of children and youth who spent 2 or more hours playing outdoors daily. The positive sign ("+") was added to stress the higher adherence to the recommendations during the weekends compared with weekdays. Data from the ALADINO study showed that during the week, 44\% of males and $33 \%$ of females aged 7 and 8 years met the recommendations, whereas during the weekend the percentage increased to $85 \%$ both in males and females. ${ }^{11}$

\section{Active Transportation: C}

Data for young children from the IDEFICS study indicated that $54 \%$ of those aged 2 to 5 years commuted actively to school, with no differences between genders. ${ }^{26}$ Data for children aged 6 to 9 years indicated that $73 \%$ of children walked on the way to school and $77 \%$ walked on the way home from school when the distance to school was less than $1 \mathrm{~km}$. The percentage declined when the distance increased to 1 to $2 \mathrm{~km}$ ( $26 \%$ and $31 \%$, respectively), to 3 to $4 \mathrm{~km}$ or more $(6 \%$ and $8 \%) .{ }^{27}$ Data from the THAO study corresponding to children aged 8 to 13 years showed that $68 \%$ of them walked to/from school. ${ }^{19}$ The percentage of adolescents that reported walking or cycling as a means of transport to/from school was $54 \%$ for males and $57 \%$ for females aged 14 years and $38 \%$ of males and $40 \%$ of females aged 18 years. ${ }^{21}$

\section{Sedentary Behaviors: $D$}

According the National Health Survey 2011 data, the guideline of less than 2 hours per day of sedentary time was met by $43 \%$ of males and $54 \%$ of females younger than 2 years, $38 \%$ of males and $40 \%$ of females from 2 to 4 years, and $45 \%$ of males and $50 \%$ of females from 5 to 14 years (this data refers to weekdays only). ${ }^{15}$ Available data from adolescents indicated that during the week only $17 \%$ of males and $26 \%$ of females aged 16 years met the guidelines. 
During the weekend the percentage decreased to $3 \%$ of males and $5 \%$ of females. ${ }^{15}$

\section{Family and Peers: INC}

There are no national data indicating parental support for PA.

\section{School: C}

According to the 2013 ALADINO study, the percentage of schools that offer access to facilities out-of-school time was $69 \%$. The percentage of schools that offered 2 or more hours of physical education per week was $68 \%$ for the second grade of primary education (7-8 years old), 55\% for the third grade (8-9 years old), and 33\% for the fourth grade (9-10 years old). ${ }^{11}$

\section{Community and the Built Environment: INC}

No data were available for this indicator.

\section{Government: INC}

There is 1 national policy, the Integral Plan for Physical Activity and Sport 2010-20, that has been developed with the aim of promoting universal access to sport for the entire population. The National Sports Council is the coordinating administrative body in the area of PA promotion, along with the Ministry of Health, Social Services, and Equality; the Ministry of Education, Culture, and Sports; and representatives of the autonomous regions and the Spanish Olympic Committee, among others. Within the Integral plan there are specific policies to promote PA at school, the workplace, the health sector, and the private sector. ${ }^{28}$ Although the policy and the strategies included are promising, a grade was not awarded because their impact on increasing PA levels in the population was not clear.

\section{Strengths and Limitations}

This is the first report that gathers information about several indicators of PA and sedentary behaviors in Spain. The results are based on a strong RWG with representation from across the country, which is a strength of this study.

Although grades are based on the best available data, there are significant research gaps. First of all, there is a need for a large national representative sample evaluating PA and sedentary behaviors according to the indicators evaluated. Second, it is necessary to harmonize the methodology to evaluate PA and time spent on sedentary behaviors. Comparing adherence to PA guidelines that have been traditionally defined based on self-report methods against PA survey data collected by objective methods can result in substantial overestimation. ${ }^{29}$

\section{Conclusion}

Spanish children and adolescents have low adherence to PA recommendations and their sedentary behavior is high. There are several gaps of information regarding key PA indicators that should be addressed by harmonizing measurement instruments, as well as establishing monitoring and evaluation systems. Lastly and most importantly, there is an urgent need to increase the levels of PA and reduce sedentary time among children and adolescents, focusing on females and adolescents.

\section{Acknowledgments}

The authors thank the following individuals for their contributions to the 2016 Spanish Report Card: Ms. Lourdes Ribas-Barba, Ms. Joy Ngo, Dr. Jonatan Ruiz, Dr. Noemi Serra-Payà, Dr. Carmen Pérez Rodrigo, and Dr. Mark Tremblay.

\section{References}

1. Griffiths LJ, Sera F, Cortina-Borja M, Law C, Ness A, Dezateux C. Objectively measured physical activity and sedentary time: crosssectional and prospective associations with adiposity in the Millennium Cohort Study. BMJ Open. 2016;11;6(4):e010366.

2. Riso EM, Kull M, Mooses K, Hannus A, Jürimäe J. Objectively measured physical activity levels and sedentary time in 7-9-yearold Estonian schoolchildren: independent associations with body composition parameters. BMC Public Health. 2016;16:346. PubMed doi:10.1186/s12889-016-3000-6

3. Marques A, Minderico C, Martins S, Palmeira A, Ekelund U, Sardinha LB. Cross-sectional and prospective associations between moderate to vigorous physical activity and sedentary time with adiposity in children. Int J Obes. 2016;40(1):28-33. PubMed doi:10.1038/ijo.2015.168

4. Poitras VJ, Gray CE, Borghese MM, et al. Systematic review of the relationships between objectively measured physical activity and health indicators in school-aged children and youth. Appl Physiol Nutr Metab. 2016;41(6, Suppl 3):S197-S239. PubMed doi:10.1139/ apnm-2015-0663

5. Carson V, Hunter S, Kuzik N, et al. Systematic review of sedentary behaviour and health indicators in school-aged children and youth: an update. Appl Physiol Nutr Metab. 2016;41(6, Suppl 3):S240-S265. PubMed doi:10.1139/apnm-2015-0630

6. van Ekris E, Altenburg TM, Singh AS, Proper KI, Heymans MW, Chinapaw MJ. An evidence-update on the prospective relationship between childhood sedentary behaviour and biomedical health indicators: a systematic review and meta-analysis. Obes Rev. 2016;17(9):833-849. doi:10.1111/obr.12426 PubMed

7. Recomendaciones para la población sobre actividad física y reducción del sedentarismo [Recommendations for the population on physical activity and the reduction of sedentary behaviour] [website]. Madrid: Ministry of Health, Social Services and Equality; 2015. http://www. msssi.gob.es/profesionales/saludPublica/prevPromocion/Estrategia/ Recomendaciones_ActivFisica.htm. Accessed May 1, 2016.

8. Mielgo-Ayuso J, Aparicio-Ugarriza R, Castillo A, et al. Physical activity patterns of the Spanish population are mostly determined by sex and age: Findings in the ANIBES study. PLoS One. 2016;11(2):e0149969. PubMed doi:10.1371/journal.pone.0149969

9. Tremblay MS, Gray CE, Akinroye K, et al. Physical activity of children: a global matrix of grades comparing 15 countries. J Phys Act Health. 2014;11(Suppl 1)S113-S125. PubMed doi:10.1123/ jpah.2014-0177

10. Colley RC, Brownrigg M, Tremblay MS. A model of knowledge translation in health: the Active Healthy Kids Canada Report Card on physical activity for children and youth. Health Promot Pract. 2012;13(3):320-330. PubMed doi:10.1177/1524839911432929

11. Estudio de prevalencia de la obesidad infantil - Estudio ALADINO (Alimentación, Actividad física, Desarrollo Infantil y Obesidad) [Childhood obesity prevalence study - ALADINO study (food, physical activity, childhood development and obesity)]. Madrid, Ministry of Health, Social Services and Equality, Spanish Food Safety and Nutrition Agency, 2013. http://www.aesan.msssi.gob.es/AECOSAN/ 
web/nutricion/detalle/iniciativa_COSI.shtml. Accessed September 1, 2015.

12. Pérez-Farinós N, López-Sobaler AM, Dal Re MÁ, et al. The ALADINO study: a national study of prevalence of overweight and obesity in Spanish children in 2011. BioMed Res Int. 2013;2013:163687. PubMed

13. Pigeot I, Baranowski T, De Henauw S, the IDEFICS Intervention Study Group. on behalf of the IDEFICS consortium. The IDEFICS intervention trial to prevent childhood obesity: design and study methods. Obes Rev. Suppl. 2015;16(Suppl 2):4-15.

14. Moreno LA, De Henauw S, Gonzalez-Gross M, et al. Design and implementation of the Healthy Lifestyle in Europe by Nutrition in Adolescence Cross-Sectional Study. Int J Obes (Lond). 2008;32:S4S11. PubMed doi:10.1038/ijo.2008.177

15. Nacional de Salud E. (ENSE) 2011/12. Madrid: Ministry of Health, Social Services and Equality; 2014. [Spanish national health survey (ENSE) 2011/12] [website]. http://www.msssi.gob.es/estadEstudios/ estadisticas/encuestaNacional/encuesta2011.htm. Accessed April 20, 2016.

16. Riddoch C, Edwards D, Page AS, et al. The European youth heart study - cardiovascular disease risk factors in children: rationale, aims, study design, and validation of methods. J Phys Act Health. 2005;2:115-129. doi:10.1123/jpah.2.1.115

17. Roberts C, Freeman J, Samdal O, et al; International HBSC Study Group. The Health Behaviour in School-aged Children (HBSC) study: methodological developments and current tensions. Int J Public Health. 2009;54:140-150. PubMed doi:10.1007/s00038-009-5405-9

18. Ruiz E, Ávila JM, Castillo A, et al. The ANIBES Study on Energy Balance in Spain: design, protocol and methodology. Nutrients. 2015;7:970-998. PubMed doi:10.3390/nu7020970

19. Gomez SF, Casas R, Palomo VT, Martin Pujol A, Fíto M, Schröder H. THAO Study protocol: effects of the THAO-child health intervention program on the prevention of childhood obesity - the POIBC study. BMC Pediatr. 2014;14:215. doi:10.1186/1471-2431-14-215 PubMed

20. Superior de Deportes C. Los hábitos deportivos de la población escolar en España. Madrid: Consejo Superior de Deportes; 2015., Available at http://www.csd.gob.es/csd/estaticos/dep-escolar/encuesta-de-habitosdeportivos-poblacion-escolar-en-espana.pdf.

21. Pérez A. Garcia-Continente X i Grup col-laborador enquesta FRESC 2012. Informe FRESC 2012: 25 anys d'enquestes a adolescents escolaritzats de Barcelona. Barcelona: Agència de Salut Pública de Barcelona; 2013. http://www.aspb.cat/arees/la-salut-en-xifres/ enquesta-fresc/.

22. Konstabel K, Veidebaum T, Verbestel V, et al; IDEFICS consortium. Objectively measured physical activity in European children: the IDEFICS study. Int J Obes (Lond). 2014;38(Suppl 2):S135-S143. PubMed doi:10.1038/ijo.2014.144

23. Aznar S, Naylor PJ, Silva P, et al. Patterns of physical activity in Spanish children: a descriptive pilot study. Child Care Health Dev. 2011;37(3):322-328. PubMed doi:10.1111/j.1365-2214.2010.01175.x

24. Moliner-Urdiales D, Ruiz JR, Ortega FB, et al; HELENA Study Group. Association of objectively assessed physical activity with total and central body fat in Spanish adolescents; the HELENA Study. Int J Obes (Lond). 2009;33(10):1126-1135. PubMed doi:10.1038/ijo.2009.139

25. de Sanidad M. Servicios sociales e igualdad. Los estilos de vida y la salud de los adolescentes españoles a lo largo de la primera década del milenio. El estudio Health Behaviour in School-aged Children (HBSC) 2002-2006-2010HBSC. 2013. http://www.msssi.gob.es/profesionales/ saludPublica/prevPromocion/promocion/saludJovenes/estudioHBSC/ docs/Comparativo2002a2010/Comparativo2002_2006_2010.pdf. Accessed January 12016.

26. Santaliestra-Pasías AM, Mouratidou T, Reisch L, et al. Clustering of lifestyle behaviours and relation to body composition in European children. The IDEFICS study. Eur J Clin Nutr. 2015;69(7):811-816. PubMed doi:10.1038/ejen.2015.76

27. Estudio ALADINO. Estudio de Vigilancia del Crecimiento, Alimentación, Actividad Física, Desarrollo Infantil y Obesidad en España 2011. Madrid: Agencia Española de Seguridad Alimentaria y Nutrición. Ministerio de Sanidad, Servicios Sociales e Igualdad; 2013.

28. Plan integral para la actividad física y el deporte [Integral plan for physical activity and sports]. Madrid: National Sports Council; 2010. http://www.csd.gob.es/csd/estaticos/plan-integral/LIBRO-PLAN-AD. pdf. Accessed May 1, 2016.

29. Hearst MO, Sirard JR, Lytle L, Dengel DR, Berrigan D. Comparison of 3 measures of physical activity and associations with blood pressure, HDL, and body composition in a sample of adolescents. $J$ Phys Act Health. 2012;9(1):78-85. PubMed doi:10.1123/jpah.9.1.78 